\title{
Solid tumors in neonates: demographic pattern and management in a tertiary care centre
}

\author{
Tripathy P.K. ${ }^{1}$, Jena P.K. ${ }^{2}$, Pattnaik K. ${ }^{3}$, Nayak M. ${ }^{4}$, Mohanty H.K. ${ }^{5}$ \\ ${ }^{1}$ Dr Prasanta Kumar Tripathy, ${ }^{2}$ Dr Pradeep Kumar Jena, ${ }^{3}$ Dr Kaumudee Pattnaik, ${ }^{4}$ Dr Mita Nayak, ${ }^{5}$ Dr Hiranya Kishor \\ Mohanty; ${ }^{1,2,5}$ authors are affiliated with Department of Pediatric Surgery, SVP PG Institute of Pediatrics, SCB Medical \\ College, Cuttack, Odisha. ${ }^{3,4}$ authors are affiliated with Department of Pathology, SCB Medical College, Cuttack, Odisha, \\ India
}

Corresponding Author: Dr Prasanta Kumar Tripathy, Consultant Pediatric Surgeon, SVP PG Institute of Pediatrics, SCB Medical College, Cuttack, Odisha, India. E-mail: drpktripathy555@gmail.com

\begin{abstract}
Background: Neonatal solid tumors are different in their clinical and biological behavior from older children. Rarity of these tumors, histological diversity and paucity of information leads to difficulty in diagnosis and management. The objective of the study is to analyse the demographic pattern, clinico-pathological features and management of neonatal solid tumors along with comparing the outcome with similar available studies. Methods: The retrospective study was carried out in a tertiary care pediatric institute between April 2014 and March 2019. The medical records of neonates admitted and operated for solid tumors were analysed. The incidence, clinical presentation, pathological findings, management and outcome were studied. Results: Out of 85 children operated for solid tumors, 24 cases were presented and operated in neonatal period. Sacrococcygeal teratoma (17 cases) was the most common neoplasm followed by retroperitoneal teratoma ( 3 cases). The male to female ratio in sacrococcygeal teratoma was almost equal in the present study. Two neonates with congenital mesoblastic nephroma and a 5-day girl with biphasic pulmonary blastoma were remarkable findings in this study. There was no mortality or tumor recurrence during postoperative period and follow up. Conclusions: Neonatal tumors are rare neoplasms and are different in their clinical and biological behavior from older children. The rarity, histological diversity and paucity of information leads to difficulty in diagnosis and management. Benign tumors may have aggressive appearance, but prognosis is good after complete surgical excision. Multidisciplinary methodological management approach is essential for optimal survival of these tiny neonates.
\end{abstract}

Keywords: Congenital mesoblastic nephroma, neonatal tumor, Pulmonary blastoma, sacrococcygeal teratoma

\section{Introduction}

Neonatal tumors are rare, heterogeneous group of neoplasms and relate to developmental events. The presentation and characteristics of these tumors are different from older children and even differ from similar neoplasms occurring latter in childhood [1,2]. Pathological diagnosis of these tumors is a challenge because of rarity, histological diversity, immaturity of newborn tissue and lack of familiarity with neonatal neoplasms. Majority are solid tumors and may be benign or malignant [3]. In a small neonate even a benign tumor can lead to significant morbidity and mortality, because of relative size and location of tumor [4].

Manuscript received: $1^{\text {st }}$ October 2019

Reviewed: $11^{\text {th }}$ October 2019

Author Corrected: $16^{\text {th }}$ October 2019

Accepted for Publication: $21^{\text {st }}$ October 2019
The risk during anaesthesia and postoperative period higher in neonates due to immature physiological status. Benign tumors can be fatal, if not completely excised. Some of these tumors may appear aggressive, leading to unnecessary aggressive therapy, which may be life threatening [5]. Majority of neonatal solid tumors are benign, but malignant neoplasms account for significant mortality. Two percent of childhood malignancies are reported during neonatal period $[3,4]$. The care of these tumors require highly skilled multidisciplinary approach, with experience in pediatric oncology [6]. Prognosis largely depends on the age at definitive treatment and tumour behaviour. Minimal environmental influence during perinatal period provides opportunity to study the biological, clinical and pathological behaviour of these tumors [2].

Pediatric Review: International Journal of Pediatric Research Available online at: www.medresearch.in 534|P a g e 


\section{Original Research Article}

The aim of the study is to find out the demographic pattern, clinic-pathological behaviour and management of neonatal solid tumors in our tertiary care hospital as well as to compare the outcome with similar available studies in literature.

\section{Material and Methods}

Setting: This study was carried out in the department of Pediatric Surgery, SVP Postgraduate Institute of Pediatrics, and department of Pathology, SCB Medical College Cuttack, Odisha, India. The medical records of patients admitted and operated for solid tumors were analysed.

Duration and type of study: The study was a retrospective study of medical case records conducted over a period of 5 years from April 2014 to March 2019.

Sampling methods: Within the above period, 85 children were operated for solid tumors, out of which 24 were in the neonatal age group and were included in the study.

\section{Inclusion criteria}

- Patients admitted and operated before one month of age,

- Patients attending the hospital before one month of age but operated subsequently after investigations and fulfilling preanesthetic criteria.

\section{Exclusion criteria}

- Patients admitted but were not operated because of refusal to give consent for surgery or those left against medical advice,

- Conditions like hemangiomas, lymphangiomas and vascular malformation.

Data collection procedure: Data in terms of age at presentation, sex, weight, site and type of tumor, operative procedure, postoperative complications, final diagnosis after histopathological study, survival during hospitalization and follow up were collected from case record for study and analysis.

Surgical procedure: As per our protocol, all patients were first resuscitated followed by hematological, biochemical and radiological investigations.

They were operated and the excised specimens were sent for histopathological study for final diagnosis. After discharge, patients were followed for minimum period of 6 months to 5 years.

Data analysis: Results were presented as percentages and as mean and median with confidence interval.

Ethical consideration: The study was conducted in accordance with ethical standards and with the revised Helsinki Declaration 2000.

\section{Results}

About 24 cases of neonatal solid tumors were operated at our institute over a period of 5 years. During this period, a total of 85 children in the age group of 0 to 14 years having solid tumors were operated. So, neonatal solid tumors constituted $28 \%$ of all solid tumors in pediatric age group. Sacrococcygeal teratoma (SCT) was the most common tumor detected in 17 cases followed by retroperitoneal teratoma (RPT) in 3 cases and congenital mesoblastic nephroma (CMN) in 2 cases. Wilm's tumor (WT) and pulmonary blastoma were also detected in one case each. There were 13 male babies and 11 female babies. The weight at presentation ranged from 2.1 to $4 \mathrm{~kg}$ with a mean weight of $3.03 \mathrm{~kg}$ (Table-1).

Table-1: Demographic pattern and outcome of neonatal solid tumors

\begin{tabular}{|c|c|c|c|c|c|c|}
\hline Diagnosis & $\begin{array}{c}\text { No of } \\
\text { cases }\end{array}$ & $\begin{array}{c}\text { Sex } \\
\text { (M:F) }\end{array}$ & $\begin{array}{c}\text { Median age in } \\
\text { days (CI) }\end{array}$ & $\begin{array}{c}\text { Median weight } \\
\text { in kg (CI) }\end{array}$ & Outcome & $\begin{array}{c}\text { Median follow up } \\
\text { in months (CI) }\end{array}$ \\
\hline SCT & 17 & $8: 9$ & $5(4.45-12.4)$ & $2.7(2.59-3.09)$ & NED-17 & $25(21.4-34.8)$ \\
\hline RPT & 3 & $2: 1$ & $28(17.7-59.5)$ & $3.6(2.93-4.07)$ & NED-3 & $39(22.8-52.4)$ \\
\hline CMN & 2 & $2: 0$ & $17.5(3-38)$ & 3.3 & NED-2 & 38 \\
\hline WT & 1 & $1: 0$ & 28 & 3.5 & NED & 12 \\
\hline PB & 1 & $0: 1$ & 5 & 3.8 & Discharged & - \\
\hline
\end{tabular}

CI - Confidence interval, NED - No evidence of disease

SCT was found in 8 male newborns and 9 female newborns with a mean age of 8.4 days (range 1 to 28 days). In spite of an obvious lump, only 3 cases presented to us on first day of life (Figure-1).

Pediatric Review: International Journal of Pediatric Research Available online at: www.medresearch.in 535|P a g e 


\section{Original Research Article}

The mean body weight was $2.84 \mathrm{~kg}$ with arrange of $2.1 \mathrm{~kg}$ to $3.7 \mathrm{~kg}$. One case of SCT had bilateral congenital talipusequinovarus as an associated anomaly. Classification system described by Altman et al (American Academy of Pediatrics Surgical Section Survey) was followed in our institute; (i) Type 1- Predominantly external with minimal presacral component, (ii) Type 2- Present externally but with significant extrapelvic extension, (iii) Type 3- Apparant externally but predominantly a pelvic mass extending into the abdomen, (iv) Type 4- Presacral with no external presentation [7].

Fifteen patients were classified as Altman type I and 2 patients as type II. They were operated in prone jack-knife position and chevron incision. Complete surgical resection of was performed in all cases of SCT along with excision of coccyx and laparotomy was not needed. Subsequent histopathological evaluation (Figure-1 A-C) confirmed the diagnosis of sacrococcygeal teratomas due to evidence of, (i) ectodermal derivatives- cystic cavity lined by epidermis and skin appendanges; (ii) mesodermal derivative- mature cartilage and (iii) endodermal derivatives- mucin secreting glands. Serum alpha-fetoprotein (AFP) which was raised in these patients according to age at measurement, gradually decreased after surgery.

Wound infection detected in 5 cases (21\%) postoperatively, was adequately managed. A normal AFP level was reported after 6-8 months after surgery and the mean follow up period was 28.1 months (range 6 to 60 months). None of our patients developed tumor recurrence and the overall cosmetic results were up to satisfaction (Figure-1 E). All the cases were advised for long term follow up.

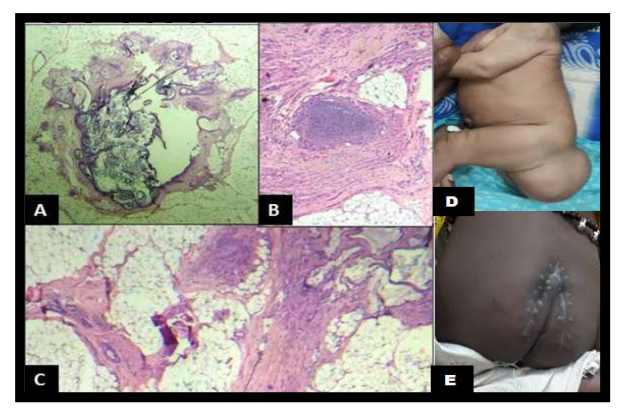

Figure-1: Sacrococcygeal teratoma: [A] Cystic cavity lined by epidermis and skin appendanges; [B] Mature cartilage; [C] Mucin secreting glands (right upper corner); [D] A large sacrococcygeal tumor; [E] Scar mark at follow up after excision through Chevron incision.

Mass abdomen was the sole presenting feature in 3 cases of RPT. CT scan revealed the provisional diagnosis in these cases. Two patients were operated within one month of age and one patient was operated beyond neonatal period. But considering the large abdominal lump, which must have been present before, the third patient was included under neonatal tumors. Postoperatively the pathological diagnosis came out to be mature cystic teratoma. There were no complications or mortality in these 3 babies and on follow up all of them were having normal AFP levels. Renal tumor was found in 3 male newborns.

All of them presented as asymptomatic abdominal mass (Figure-2 a). There was no history of hematuria or hypertension and contrast enhanced CT scan suggested renal tumors (Figure-2 b,c). After initial stabilization, radical nephroureterectomy was performed in these patients. Histopathology revealed CMN in two cases (Figure-2 d). Densely cellular proliferations of thick interlacing bundles of spindle cells with elongated nuclei and mitotic activities were seen. Entrapment and infiltration of renal tubules and glomeruli in the interstitium were common in contrast to Wilm's tumor and metanephric stromal tumors. Both the cases of CMN were of cellular variety.

Wilm's tumor was detected in one case(Figure-2 e), which was having a triphasic appearance, constituted by (i) embryonic tubular structures of epithelial components, (ii) closely packed small round to oval cells with high nuclear-tocytoplasmic ratio and course chromatin pattern of blastemal patterns and (iii) myxoidspindloidmesenchymal cells of stromal components. Wilm's tumor patient had received adjuvant chemotherapy. All the renal tumor cases were under follow up, asymptomatic at present without any recurrence.

Pediatric Review: International Journal of Pediatric Research Available online at: www.medresearch.in 536|P a g e 


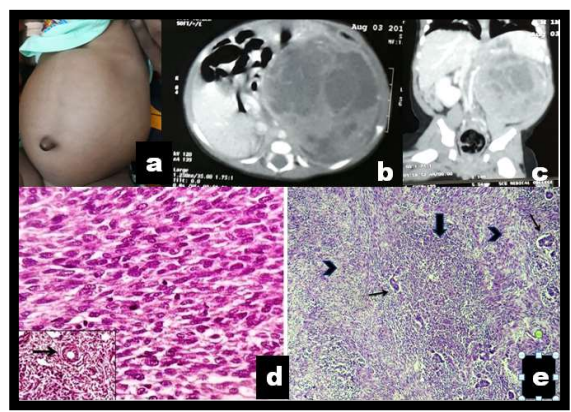

Figure-2: Renal tumors:[a] New-born with visible abdominal mass ; [b] Congenital mesoblastic nephroma - CT scan abdomen, axial and [c] Coronal image showing left sided heterogeneously enhancing large tumor crossing the midline; [d] Histopathology: Densely cellular proliferations of thick interlacing bundles of spindle cells with elongated nuclei with mitotic activities. H\&E: 400X Inset: entrapped the renal tubules in the interstitium within the tumor mass (arrow). H\&E: 100X- features suggestive of congenital mesoblastic nephroma; [e] Wilm's Tumor histopathology: embryonic tubular structures of epithelial elements (thin arrows), small round to oval cells of blastematous elements (thick arrow) and loose mesenchymal stromal tissue (chevrons).

A 5-day female newborn presented with respiratory distress since day 1 of life. Chest radiography showed homogenous tissue opacity within the right lower lung field. Uitrasonography suggested hypoechoic lesion with no internal vascularity in right hemithorax. Further investigation with CT scan thorax (Figure-3 a) revealed a well marginated oval soft tissue attenuation ( $\mathrm{HU}=35-40)$ lesion seen in right lung, lower lobe region. The size of the mass was 45X50 MM and it extended medially to peribronchiolar location. With a provisional diagnosis of bronchogenic cyst/mass, the newborn underwent right sided thoracotomy through $5^{\text {th }}$ intercostal space (Figure-3 b). A solid lesion involving whole of right lower lobe was found and the mass was excised by lobectomy (Figure-3 c, d).

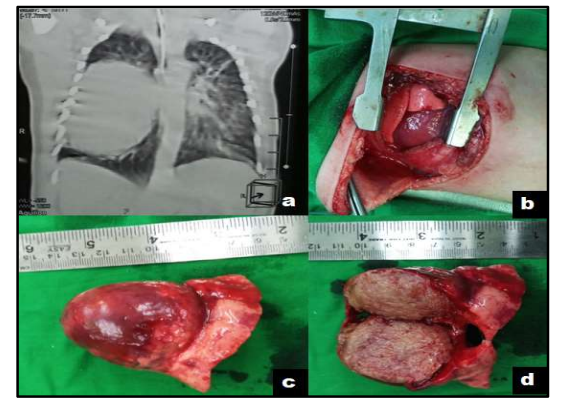

Figure-3: Pulmonary blastoma [a] CT scan-well marginated oval soft tissue lesion in right lung; [b] Intraoperative picture, right side thoracotomy; [c] Excised pulmonary mass; [d] Cut surface of pulmonary tumor. Postoperative period was uneventful, and neonate was discharged on breast feeds. The histopathological study of pulmonary mass (Figure-4 A) showed a biphasic growth pattern of epithelial as well as mesenchymal components, which had a primitive appearance. Epithelial lining cells were low columnar with clear cytoplasm. No differentiation elements were evident in the mesenchymal components. Immunohistochemistry stain (EMA \& Vimentin) was applied to both the components to confirm their biphasic origin (Figure-4 B, C). So, the histology revealed a rare diagnosis of pulmonary blastoma, which was confirmed by immunohistochemistry. The patient had completed one year follow up till the end of study and there was no evidence of recurrence or metastasis.

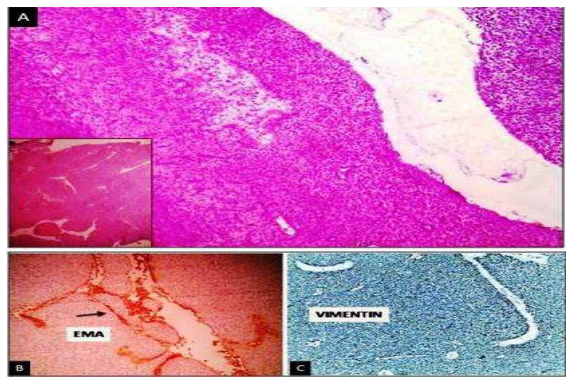

Pediatric Review: International Journal of Pediatric Research Available online at: www.medresearch.in 537|P a g e 


\section{Original Research Article}

Figure-4: Pulmonary Blastoma: [A] Immature epithelial cell lining with surrounding cellular mesenchymal cells. H\&E 100X; Inset: 40X [B] EMA immunostain: Epithelial cell surfaces show positivity [C] Vimentin: Mesenchymal cells show cytoplasmic positivity.

\section{Discussion}

This study detected 24 neonatal solid tumors over a period of 5 years. So, these tumors are rare, but they are unique in this age group. Sacrococcygeal teratoma was the commonest tumor detected in the present study. SCT is also reported as most common congenital tumor in neonates [7-9]. The annual incidence is higher in our centre as compared to similar published studies [8-10]. Out of a total number of 20 children ( 0 to 14 years) with SCT operated in our hospital during the study period, 17 were operated during neonatal period. Two third of cases of SCT are described in neonatal period [11], similar to our finding. A female predominance (3 to $4: 1)$ is reported in this congenital anomaly in literature $[8,9,12]$. However, the present study revealed almost equal male to female ratio. The exact cause is not known to us at this point of time. It was suspected that less number of female newborns are presenting to us from periphery despite of an obvious external anomaly. Also, $41 \%$ of cases attended the hospital after one week of life, in spite of a visible congenital disorder.

Associated anomalies are described in $5-26 \%$ cases of SCT [8-10]. It was observed that talipusequinovarus as an association in one of our case (6\%). Sinha et al. also reported equinus deformity of foot in one of their cases [8]. Type I tumor is most commonly reported in $80 \%$ cases among neonates with SCT $[8,9]$. Type I in $88 \%$ and type II in $12 \%$ of cases was observed, but type III and IV were not documented. All the neonates in our series were operated by sacrococcygeal approach with coccygectomy and laparotomy was not needed. Although, Aly et al. required laparotomy in one of their cases, Sinha et al. did not require laparotomy in any of their cases. So, our findings corroborated with the published studies [8,9]. Malignant risk increases with age and risk of malignancy in neonatal SCT is rare [1012]. Recurrence of SCT after complete excision along with coccyx is unusual among neonates. Serum AFP is a reliable marker for recurrence. In the present study, any recurrence in our operated cases of SCT during our follow up period was not observed. Long term follow up is necessary in SCT even during adulthood.

Although, congenital teratomas occur most commonly in sacrococcygeal region; mediastinum, head and neck and retroperitoneum are also affected [13]. RPT account for 3.5 to $4 \%$ of germ cell tumors in pediatric age group $[14,15]$. Malignancy is very uncommon in RPT $[16,17]$.
Complete excision was done in all 3 cases of our RPT and no evidence of malignancy was noted on histopathological study. Complete excision is curative for these teratomas and prevent recurrence [15]. Congenital mesoblastic nephroma is a rare stromal neoplasm, usually presenting as asymptomatic abdominal mass [18]. It typically affects young infants and is reported as commonest kidney tumor in children below 3 months of age $[4,19]$. Two histological types of CMN are recognized, (i) classical type (24\%) representing purely benign, (ii) cellular type (66\%) having aggressive pathological behaviour $[18,20]$. A mixed variant containing features of both the types is also encountered in $10 \%$ cases [19]. Although classical variety is more common in infants below 3 months of age, both of our cases were of cellular variety. Differentiation between WT and CMN, particularly the cellular variety is difficult even during histopathological study [4]. Chances of misdiagnosis should be remembered due to resemblance with more common renal tumors and lack of familiarity with this rare neonatal tumor. So, authors believe that this is an underreported pediatric renal neoplasm [18]. In spite of the benign nature, $\mathrm{CMN}$ can metastasize and there are chances of recurrence in $5-10 \%$ cases [20]. Although nephrectomy is adequate treatment for CMN, infants should be followed due to potential risk of malignancy, especially the cellular variant. Chemotherapy is not recommended in stage I and II CMN, but its beneficial role has been described in stage III and IV cellular type, particularly in infants above 3 months age [19]. In spite of having cellular histology, chemotherapy was not given to our cases of CMNs as both the children were below one month of age and of stage II. There is no evidence of recurrence or malignancy at one year and 5 year follow up in our individual cases. The neonate with WT had triphasic histological pattern and received chemotherapy as per schedule. Long term follow up is advised in all cases of renal tumors and continuing.

One case of pulmonary blastoma was detected in the present study, which is a rare primary pulmonary malignancy. Lung masses in children are mostly metastatic or inflammatory in nature. Primary, metastatic and inflammatory pulmonary lesions occur in a ratio of 1:5:60 [21,22]. Traditionally, the blastomatous pulmonary tumors, which mimic embryonic structures of developing lung were mentioned under an umbrella 
name 'pumonary blastoma' [23]. Subsequently they were divided into 3 distinct pathologies as recommended by WHO classification system of pulmonary tumors [24,25], (i) classical biphasic pulmonary blastoma (CBPB), (ii) well differentiated fetal adenocarcinomas (WDFA) and (iii) Pleuropulmonaryblastoma (PPB), occurring almost exclusively in children. CBPB usually occur in adults and commonly mentioned as adult-onset pulmonary blastoma. They exhibit biphasic histological pattern containing both epithelial and mesenchymal components $[23,26]$. They are different from childhood onset $\mathrm{PPB}$, which have monophasic pattern showing features of mesenchymal malignant component only $[22,26]$.

Although, our patient was a 5-day female neonate, the histology and immunohistochemistry reports were consistent with adult-onset CBPB. On extensive survey of English literature, in the present study, this type of pulmonary blastoma being reported in such a perinatal age group was not observed. CBPB is a very aggressive malignancy, commonly seen in adult males with history of smoking and having a peak incidence on $4^{\text {th }}$ decade of life [26,27]. However, the tumor was completely excised and newborn had uneventful postoperative recovery period. Patient was discharged in good general condition and on breast feeds. A panel of histopathology as well as immunohistochemical studies revealed a rare diagnosis of biphasic, highly malignant pulmonary blastoma and this is a remarkable finding in the present study.

Limitations of the study: A study having large number of samples size was not possible, because of rarity of neonatal solid tumors. Due to paucity of objective information, individual experiences can only provide insight for further studies and promote cancer research.

\section{Conclusion}

Neonatal solid tumors are rare neoplasms that are different in presentation and characteristics from older children. The rarity, hisological diversity and lack of familiarity leads to difficulty in diagnosis and further management of these tumors. Benign tumors may be life threatening because of relative large size in a small newborn in presence of immature physiological status. Extragonadal germ cell tumors were most common neonatal solid tumors detected in this study and sacrococcygeal region was the most preferred site. The male to female ratio of sacrococcygeal teratomas was almost equal in contrast to gross female preponderance

\section{Original Research Article}

reported in most of the published studies. In spite of aggressive appearance and clinical behaviour, the outcome is usually favourable due to unique biological features. Two cases of cellular variety of congenital mesoblastic nephroma and one case of biphasic pulmonary blastoma detected in neonatal period are extremely rare anomalies and remarkable feature in this study. A methodological multidisciplinary approach is essential for survival of these newborns. Further studies on developmental events in oncogenesis, genetic and environmental factors related to pathogenesis of neonatal tumors are required for novel cancer therapy.

\section{What the study adds to the existing knowledge?}

Neuroblastomas contributed a significant percentage of cases in studies on neonatal solid tumors, but neuroblastoma in neonates during the study period was not observed; Although sacrococcygeal tumors were detected as the most common tumor, In the present study, a female preponderance as reported in most published studies was not observed. The classical variety of CMN usually present earlier, before 3 months of age and cellular variety present latter, usually after 3 months of age. However, in the present study both the neonates with CMN were of cellular type; Pulmonaryblastoma usually occur in adults with male preponderance and common among smokers. To the best of author's knowledge, pulmonary blastoma being detected in a 5-day female new born in the present study, is first such report of this kind in literature; Twothirds of patients with CBPB die within 2 years regardless of management approach due to high incidence of metastasis and recurrence during first year of life. But our patient of CBPB is totally asymptomatic without any evidence of metastasis or recurrence in her second year of life. So, there is a difference in the clinical and biological behaviour of this primary lung cancer from adult-onset cases.

\section{Author's contribution}

- Dr. Prasanta Kumar Tripathy: Concept of work, data acquisition, analysis and drafting the work,

- Dr. Pradeep Kumar Jena: Design of work and revising work critically,

- Dr. Kaumudee Pattnaik: Data acquisition and interpretation of data,

- Dr. Mita Nayak: Data acquisition and interpretation of data,

- Dr. Hiranya Kishor Mohanty: Final approval of the version to be published 


\section{Original Research Article}

\section{References}

1. Orbach D, Sarnacki S, Brisse HJ, Villars MG, Jarreau PH, Tsatsaris V, et al. Neonatal cancer. Lancet Oncol. 2013;14(13): e609-e620. doi: 10.1016/S1470-2045(13) 70236-5.

2. Moore SW. Neonatal tumors. Pediatr Surg Int. 2013;29 (12): 1217-1229.doi: 10.1007/s00383-0133424-3.

3. Desdandes E, Guissou S, Ducassou S, Lacour B. Neonatal solid tumors: incidence and survival in France. Pediatr Blood Cancer. 2016;63(8);1375-1380. doi:10.1002/pbc.26006.

4. Chandrasekaran A. Neonatal solid tumors. Pediatr Neonatal. 2018;59(1):65-70. doi: 10.1016/j.pedneo. 2016.12.007.

5. Charles AK. Congenital tumors. In: Jean W Keeling, T Yee Khong. Editors. Fetal and Neonatal Pathology $4^{\text {th }}$ Ed. London: Springer 2007.Pp. 327-378.

6. Raciborska A, Bilska K, Węcławek-Tompol J, Ussowicz M, Pogorzała M, Janowska J, et al. Solid Cancers in the Premature and the Newborn: Report of Three National Referral Centers. Pediatr Neonatol. 2016;57(4):295-301. doi: 10.1016/j.pedneo. 2015.08. 007.

7. Altman RP, Randolph JG, Lilly JR. Sacrococcygeal teratoma: American Academy of Pediatrics Surgical Survey-1973. J Pediatr Surg. 1974;9(3):389-398. doi:10.1016/s0022-3468(74)80297-6.

8. Sinha S, Sarin YK, Deshpande VP. Neonatal sacrococcygeal teratoma: Our experience with 10 cases. J Neonatal Surg 2013;2(1):4.

9. Aly KAE, Shoier M, Badrawy T. Sacrococcygeal teratoma: a neonatal surgical problem. Ann Pediatr Surg. 2006; 2(2):106-111.

10. Bedabrata M, Das C, Sengupta M, Saha AK, Mukhopadhyay M, Mukhopadhyay B. An epidemiological review of sacrococcygeal teratoma over five years in a tertiary care hospital. Ind J Med Pediatr Oncol. 2018;39(1):4-7. doi: 10.4103/ijmpo. ijmpo_239_14.

11. Stevens MCG. Neonatal tumors.Arch Dis Child. 1988; 63:1122-1125.
12. Rescorla FJ. Teratoma and other germ cell tumors. In: Coran AG, Adzick NS, Krummel TM, Laberge J, Shamberger RC, Caldmone AA. Editors. Pediatric Surgery. $7^{\text {th }}$ ed. Philadelphia: Elsevier Saunders 2012. Pp. 507-16.

13. Choudhury SR, Debnath PR, Pant N, Chowdhary L. Congenital immature teratoma of the retroperitoneum. J Neonatal Surg. 2013;2(3):33. eCollection 2013 Jul-Sep.

14. Annigeri VM, Bhuvanesh A, Gadgade BD, Halgeri AB. Giant retroperitoneal mature cystic teratoma in an infant: A case report. J Pediatr Neonatal Care. 2016;5 (7):00212. doi: 10.15406/jpnc.2016.05.00212

15. Tripathy PK, Pattnaik K, Jena PK, Mohanty HK. Retroperitoneal mature cystic teratoma in a 3-month-old infant: A case report and literature review. Indian J Med Paediatr Oncol. 2018;39(1):117-119. doi: 10.4103/ ijmpo.ijmpo_42_17.

16. Aldhilan A, Alenezi K, Alamer A, Aldhilan S, Alghofaily K, Alotaibi M. Retroperitoneal teratoma in 4 months old girl: Radiology and pathology correlation. Curr Pediatr Res. 2013;17(2):133-136.

17. Chaudhary A, Misra S, Wakhlu A, Tandon RK, Wakhlu AK. Retroperitoneal teratomas in children. Indian J Pediatr. 2006;73(3):221-223. doi: 10.1007/ bf02825485

18. Tripathy PK, Behera S, Mohanty HK. Cellular Congenital Mesoblastic Nephroma in a Newborn. J Neonat Surg. 2017;6(2):45. doi: 10.21699/jns.v6i2.564.

19. Wang ZP, Li K, Dong KR, Xiao XM, Zheng S. Congenital mesoblastic nephroma: Clinical analysis of eight cases and a review of the literature. Oncol Lett. 2014;8(5):2007-2011. Epub 2014 Sep 1. doi: 10.3892/ ol.2014.2489.

20. Mallya V, Arora R, Gupta K. Congenital Mesoblastic Nephroma: A Rare Pediatric Neoplasm/ Kongenital Mezoblastik Nefrom: Nadir Bir Pediatrik Tümör. Turk J Pathol. 2013;29(1):58-60. doi: https:// doi.org/ 10.5146/tjpath.2013.01149.

21. Wahid FN, Malkan AD, Bahrami A, Pappo AS, Sandoval JA, Fernandez-Pineda I, Rao BN. Primary lung tumors in children and adolescents:29 years of experience at a single institution. Clin Surg.2017; 2:1666.

Pediatric Review: International Journal of Pediatric Research Available online at: www.medresearch.in 540|P a g e 


\section{Original Research Article}

22. Dishop MK, Kuruvilla S. Primary and metastatic lung tumors in the pediatric population: a review and 25-year experience at a large children's hospital. Arch Pathol Lab Med. 2008;132(7):1079-1103. doi: 10.1043/ 1543-2165 (2008)132 [1079:PAMLTI] 2.0.CO;2.

23. de Kock L, Bah I, Brunet J, Druker H, Astigarraga I, Bosch-Barrera J, et al. Somatic DICER1 mutations in adult-onset pulmonary blastoma. Europe Resp J. 2016;47(6):1879-1882. doi: 10.1183/13993003.001722016.

24. Brambilla E, Travis WD, Colby TV, Corrin B, Shimosato Y. The new World Health Organization classification of lung tumours. Eur Respir J. 2001;18 (6):1059-1068. doi: 10.1183/09031936. 01.00275301.
25. Smyth RJ, Fabre A, Dodd JD, Bartosik W, Gallagher CG, McKone EF. Pulmonary blastoma: a case report and review of the literature. BMC Res Notes. 2014; 7:294. doi: 10.1186/1756-0500-7-294.

26. Alahwal MS, Maniyar IH, Saleem F, Alshiekh M. Pulmonary blastoma: a rare primary lung malignancy. Case Rep Med. 2012; 2012:471613. doi: 10.1155/ 2012/471613. Epub 2012 Sep 19.

27. Cutler CS, Michel RP, Yassa M, Langleben A. Pulmonary blastoma: case report of a patient with a 7-year remission and review of chemotherapy experience in the world literature. Cancer: Interdisciplinary Int J Am Cancer Soc. 1998;82(3):462467.

\section{How to cite this article?}

Tripathy P.K., Jena P.K., Pattnaik K., Nayak M., Mohanty H.K. Solid tumors in neonates: demographic pattern and management in a tertiary care centre. Int J Pediatr Res.2019;6(10): 534-541.doi:10.17511/ijpr.2019.i10.07 